\title{
INCREASING PROTEIN INTAKE TO HELP OLDER ADULTS INCREASE MUSCLE STRENGTH AND FUNCTION: A PILOT, SINGLE-ARM INVESTIGATION USING COACHING AND A PER-MEAL PROTEIN PRESCRIPTION
}

\author{
S.S. Gropper ${ }^{1}$, M. Exantus ${ }^{1}$, K.L. Jackson ${ }^{1}$, S.M. Spiers ${ }^{2}$, E.R. Vieira ${ }^{3}$, D. D'Avolio ${ }^{1}$, A. Opalinski ${ }^{1}$, R. Tappen ${ }^{1}$
}

\begin{abstract}
Objective: To evaluate the effects of nutrition education, diet coaching, and a protein prescription (PP) on protein intake, and associations with muscle strength and function. Design: Prospective pretest posttest single-arm study. Setting: Urban area, East coast of South Florida. Participants: 20 white, non-Hispanic adults, aged $73.3 \pm 10.4$ years. Intervention: 10-week telephone-based diet coaching, nutrition education and a per-meal PP. Measurements: Protein and energy intakes, weight, grip strength (GS), and 5-chair-rise (5CR), timed up and go (TUG), 3-meter walk (3mW) tests at baseline and 10 weeks. Results: Pre to 10 -week post values significantly improved $(\mathrm{p}<0.05)$ for protein intake/ $\mathrm{kg}$ body weight $(0.8 \pm 0.3$ to $1.2 \pm 0.3 \mathrm{~g})$, protein intake/meal (17.2 $\pm 4.8 \mathrm{~g}$ to $26.4 \pm 6 . \mathrm{g})$, protein intake/100 kcal (3.74 \pm 1.16 to $5.97+0.98 \mathrm{~g}), \mathrm{GS}(22.4$ to $23.4 \mathrm{~kg})$, and times for TUG (10 to $8 \mathrm{sec}), 3 \mathrm{~mW}$ (4 to $3 \mathrm{sec}$ ), and 5CR (13 to 11sec). Conclusions: Given the positive findings of this unique pilot investigation, additional studies, which include a larger more diverse group of participants and provide for control group(s), are needed to better investigate the effectiveness of this approach and its effects on muscle strength and function.
\end{abstract}

Key words: Protein intake, coaching, strength.

\section{Introduction}

The synthesis of body proteins, including muscle, requires the consumption of the appropriate amounts of essential amino acids from protein-containing foods. Many older adults fail to consume enough protein (1, 2 ). An uneven/skewed protein intake pattern is also common in the United States, with adults typically ingesting the majority of protein at the evening meal, and the least amount at breakfast $(1,2)$. Inadequate protein intake along with skewed protein distribution among meals has been associated with reduced muscle protein synthesis, muscle mass, strength, and physical/functional performance (3-6). Sarcopenia, characterized by reduced muscle mass, strength and function, is associated with aging and exacerbated by low protein ingestion (7).

A per-meal high-quality protein intake of $20-35 \mathrm{~g}$ has been suggested to improve protein synthesis needed for muscle protein repair and maintenance, and to sustain muscle mass, strength and function in older adults (8-10).

1. Christine E Lynn College of Nursing, Florida Atlantic University, Boca Raton, FL, USA; 2. School of Medicine, St. George's University, Grenada, West Indies; 3. Department of Physical Therapy, Florida International University, Miami, FL, USA.

Corresponding Author: Sareen S. Gropper, Christine E Lynn College of Nursing, Florida Atlantic University, 777 Glades Road, Boca Raton, FL 33432. Phone 561297 3614; Fax 561297 2416; Email sgropper@health.fau.edu
Studies examining the effects of protein on muscle have typically provided participants with supplements (whey, casein- or soy-based powders or amino acids) versus allowing participants to self-select protein-rich foods (10-14). Coaching has been used successfully to help adults change dietary behaviors, primarily improving food choices to reduce disease risks associated with type 2 diabetes, heart disease, and obesity (15-18). Missing from the literature, and which will be fulfilled from this study, is the use of coaching for the purpose of helping adults to improve their protein intake and the use of protein-rich foods (not supplements) to improve muscle strength and physical function. This pilot study examined the effects of nutrition education, diet coaching and a per-meal protein prescription on dietary protein intake (with participants self-selecting protein-rich foods), and associations with muscle strength and physical function in a group of older adults.

\section{Methods}

\section{Participants, design, and setting}

This 10-week prospective, single-arm pilot study, using a pretest posttest design approach, recruited participants from a low-income residential-living community, a 
congregate meal site, and a hospital-affiliated center in an urban area on the east coast of South Florida. Participant inclusion criteria were 55 years or older, self-reported as healthy (without cognitive impairments assessed using the Mini-Cog (19) screening test), English speaking/reading, able to communicate by telephone, and consuming $<0.4 \mathrm{~g}$ protein $/ \mathrm{kg}$ body weight at two or more meals/day (assessed from a 3-day dietary recall taken at baseline). Exclusion criteria included a renal disease diagnosis and vegan diet. The study was approved by the University's Institutional Review Board for the Protection of Human Subjects in Research. This trial is registered at clinicaltrials.gov as NCT04378556.

\section{Procedures}

Sociodemographic information (sex, age, country of birth, and education-level) was collected at baseline. Height was assessed using a height rod at baseline and weight was measured using an electronic scale (Healthometer, Model 349KLX, McCook, IL) at baseline and 10-weeks. Height and weight were used to calculate Body Mass Index (BMI, in $\mathrm{kg} / \mathrm{m}^{2}$ ).

Nutritional status was assessed at baseline using the mini-nutritional assessment (MNA) short form, which is a well-known, validated tool for assessing risk of malnutrition in older community-dwelling adults (20, 21). The MNA includes questions on food intake/recent appetite, unintentional recent weight loss, mobility, the presence of acute disease or psychological stress (illness, bereavement), the presence of neuropsychological problems (dementia, depression), and body mass index. The maximum attainable score is 14 , with scores $>12$ indicating normal nutritional status, scores of $8-11$ indicating risk for malnutrition, and scores $<8$ indicating malnutrition $(20,21)$.

Protein, carbohydrate, fat, and energy ( $\mathrm{kcal}$ ) intakes were assessed at baseline, 5 and 10-weeks from three (2 weekdays and 1 weekend day) 24-hour diet recalls at each time point. Dietary recalls were collected using multiplepass dietary recall methodology and analyzed using diet analysis software (ESHA, Salem, OR). This nutrition analysis software program, widely used for research studies, has an extensive food and nutrient database of more than 100,000 foods $(22,23)$. The software database includes, for example, data from the United States Department of Agriculture Standard Reference database (which provides the basis for most food composition databases) as well as from food manufacturers and restaurants. Mean protein intake at meals, obtained from the analysis of three 24-hour dietary recalls taken at baseline, was used to determine if participants were consuming $<0.4 \mathrm{~g} / \mathrm{kg}$ body weight at two meals and met study inclusion criteria. Protein intake $(\mathrm{g} / \mathrm{kg}$ body weight) was also compared to the Recommended Dietary Allowance (RDA) for protein $(0.8 \mathrm{~g}$ protein $/ \mathrm{kg}$ body weight $)$ and protein requirement $(0.66 \mathrm{~g}$ protein $/ \mathrm{kg}$ body weight) (24). The macronutrient contents of the diet were also calculated as a percentage of energy at baseline and 10-weeks.

The following well-established strength and functional tests were completed at baseline and 10-weeks: dominant-hand grip strength (GS) (Jamar dynamometer, Performance Health, Cedarburg, WI), timed up and go (TUG) test, and the Short Physical Performance Battery (SPPB) consisting of timed measures of balance, 3-meter walk $(3 \mathrm{~mW}) /$ gait speed, and 5 -chair rises (5CR) (7, 25-27). The TUG, $3 \mathrm{~mW}$, and grip strength assessments were each completed three times, with the average value used for statistical analyses. GS, 5CR, and gait speed measurements at baseline and 10 weeks were compared with cut-off points used to assess risk for sarcopenia. The cut-off values used for GS were $<27 \mathrm{~kg}$ for men and $16 \mathrm{~kg}$ for women, for 5CR times $>15$ sec., for gait speed $<0.8$ meters / seconds, and for TUG times $>20$ seconds (7).

The week following baseline data collection, participants met individually with a Registered Dietitian and received a per-meal protein prescription $(0.4 \mathrm{~g}$ protein $/ \mathrm{kg}$ body weight/meal) and nutrition education (verbally and written) addressing protein-containing food sources and food portion sizes needed to meet the protein prescription. Diet coaching sessions were provided by telephone once/week over the next 9 weeks and were focused on helping participants improve protein-rich food selections at meals. The coaching process was based on the Health and Wellness Nurse-coaching Model (28). Fundamental elements of the coaching process included structured interactions, a person-centered focus, goal setting, and facilitation of a process of personal dietary behavior change. Goals, set weekly by participants, were specific, measurable, achievable and realistic. Some of the techniques used to facilitate the process of personal dietary behavior change as well as to empower and motivate participants to help them to achieve their goals and overcome barriers/obstacles included motivational interviewing, intentional listening, affirmation, and somatic awareness (29).

To ensure fidelity, coaching sessions were scripted. Coaching sessions lasted about 25-30 minutes during the first 5-weeks; sessions lasted about 15-20 minutes during the remainder of the study period. During weeks 3 and 8, group nutrition education was also provided. Participants were instructed not to change exercise habits or to try to gain or lose weight during the study.

\section{Statistical analyses}

Dietary protein and energy intakes, grip strength, TUG, 3mW, 5CRT, and SPPB scores were analyzed using repeated measures analysis of variance (InStat, GraphPad Software, San Diego, CA). Statistically significant findings from repeated measures ANOVA were followed by a Tukey's test. A p-value of $<0.05$ indicated statistical significance. 


\section{Results}

\section{Participants and Study Adherence}

Twenty white, non-Hispanic adults (15 females, 5 males), aged $73.3 \pm 10.4$ years, completed the study. Two additional participants began the study but withdrew due to non-study related illness. The participants' education levels were: $30 \%$ graduated high school without further education, 20\% some college (less than 4 years), 30\% college degree, and $20 \%$ post-college education. None of the participants reported taking corticosteroids or other anti-inflammatory medications on a daily basis. Body mass index (BMI), calculated from weight and height values at baseline, averaged $25.2 \pm 4.2 \mathrm{~kg} / \mathrm{m}^{2}$; 12 participants had a BMI between $18.5-24.9 \mathrm{~kg} / \mathrm{m}^{2}$, five had a BMI $25-29.9 \mathrm{~kg} / \mathrm{m}^{2}$, and three had a BMI > $30 \mathrm{~kg} / \mathrm{m}^{2}$. Weight at baseline averaged $68.3 \pm 16.8 \mathrm{~kg}$ and did not significantly differ from the end-of-study weight of $68.3 \pm 16.7 \mathrm{~kg}$. MNA scores averaged 12, with a range of 9-13; based on the MNA scores, four of the 20 participants were classified as "at risk for malnutrition". Nineteen of the 20 participants engaged in at least $70 \%$ of coaching sessions.

\section{Dietary Protein and Energy Intakes}

Protein intake per meal, per kg body weight, and per $100 \mathrm{kcal}$ increased significantly from baseline to weeks 5 and 10, with no significant differences between weeks 5 and 10 (Table 1). At baseline $23 \pm 17 \%$ of meals met the per-meal protein prescription versus $51+25 \%$ at week 10 $(\mathrm{p}<0.01)$. Energy intake did not significantly differ over time (baseline: $1465 \pm 499 \mathrm{kcal}$, week 5: $1593 \pm 524 \mathrm{kcal}$, and week 10: $1393 \pm 375 \mathrm{kcal})$.

The percentages of energy from protein at baseline and at 10 weeks were $17 \pm 5 \%$ and $23+4 \%$ respectively, from carbohydrate were $45 \pm 9 \%$ and $41 \pm 7 \%$ respectively, and from fat were $37 \pm 8 \%$ and $35 \pm 7 \%$, respectively. The percentage of energy from protein, but not from carbohydrate and fat, at baseline versus week 10 differed, with a significantly $(p=0.0001)$ higher percentage of

energy from protein observed at the end of the study versus baseline.

At baseline, four participants (20\%) consumed less than the protein requirement, and six (30\%) ingested less than the protein RDA (24). At week 10, no participants consumed less than the protein requirement, and two (10\%) participants consumed just below the RDA, averaging $0.76 \mathrm{~g}$ and $0.79 \mathrm{~g}$ protein $/ \mathrm{kg}$ body weight/ day.

\section{Muscle Strength and Physical Function}

Significant improvements were observed for GS, TUG, $3 \mathrm{~mW}$, and 5CR between baseline and 10 weeks (Table 2). No significant change in the SPPB score was found.

Table 2

Grip strength, timed up and go, 3m walk, 5-chair rise, and Short Physical Performance Battery (SPPB) score at baseline and after 10-weeks of increased dietary protein intake in a group of older adults

\begin{tabular}{llll}
\hline & Baseline & 10-weeks & p-value \\
\hline Grip Strength* $\left.{ }^{*} \mathrm{~kg}\right)$ & $22.4 \pm 8$ & $23.4 \pm 8$ & 0.005 \\
Timed Up and Go (sec) & $10 \pm 3$ & $8 \pm 2$ & 0.010 \\
3m walk (sec) & $4 \pm 1$ & $3 \pm 1$ & 0.001 \\
5-Chair Rise (sec) & $13 \pm 4$ & $11 \pm 3$ & 0.010 \\
SPPB Score & $10 \pm 2$ & $10 \pm 2$ & 0.249 \\
\hline
\end{tabular}

${ }^{*}$ Grip strength data from 18 participants.

At baseline, one male and one female had a GS below the cut-off points for sarcopenia risk (i.e. $<27$ $\mathrm{kg}$ and $16 \mathrm{~kg}$, respectively) (7); at 10-weeks, GS for these participants were still below the cut-off values. At baseline, six participants had 5CR times $>15$ seconds, indicating poor lower body muscle strength and indicative of sarcopenia (7). However, by 10-weeks, only one participant exhibited times in excess of this cutoff value. No participants exhibited a gait speed $<0.8$ meters/seconds or TUG times $>20$ seconds, characteristic of sarcopenia and frailty (7).

Table 1

Protein intake at baseline and after 5 and 10 weeks of nutrition education and coaching in a group of older adults

\begin{tabular}{lcccc}
\hline Protein Intake (g) & Baseline & 5-weeks & 10-weeks & p-value \\
\hline Breakfast (g) & $10.9 \pm 6.5^{\mathrm{a}}$ & $24.9 \pm 9.5^{\mathrm{b}}$ & $21.2 \pm 9.4^{\mathrm{b}}$ & 0.001 \\
Lunch $(\mathrm{g})$ & $17.5 \pm 6.4^{\mathrm{a}}$ & $28.8 \pm 6.1^{\mathrm{b}}$ & $27.2 \pm 11.9^{\mathrm{b}}$ & 0.010 \\
Dinner (g) & $22.6 \pm 10.2^{\mathrm{a}}$ & $28.4 \pm 6.8^{\mathrm{b}}$ & $30.6 \pm 8.5^{\mathrm{b}}$ & 0.002 \\
Per kg body weight & $0.8 \pm 0.3^{\mathrm{a}}$ & $1.3 \pm 0.3^{\mathrm{b}}$ & $1.2 \pm 0.3^{\mathrm{b}}$ & 0.0001 \\
Per 100 kcal & $3.74 \pm 1.16^{\mathrm{a}}$ & $5.62 \pm 1.43^{\mathrm{b}}$ & $5.97 \pm 0.98^{\mathrm{b}}$ & 0.0001 \\
\hline
\end{tabular}

a,b Values with different letter superscripts are statistically significantly different 


\section{Discussion}

This investigation is believed to be the first to provide participants with a per-meal protein prescription, nutrition education, and diet coaching aimed at improving protein intake among participants through participant's self-selection of protein-rich food sources. This approach not only helped to increase protein intake at each meal and thus daily protein intake, but also provided for a more even distribution of protein throughout the day.

Protein intake by participants at baseline was found to be skewed with the lowest intake observed at breakfast and the highest intake at dinner. This finding was expected and similar to that observed in other studies $(1,2)$. The per-meal protein prescription and coaching helped participants identify protein-rich foods which could be consumed at breakfast and lunch to improve protein intake. Other studies have also demonstrated significant improvements in protein intake in adult participants; however, these studies have provided the participants with essential amino acid mixtures, protein powders (usually whey- or milk-based), or other proteincontaining supplements for ingestion at specified times (10-14). The approach used in this study is thought to more closely reflect real life dietary habits, permit more diversity within the diet, and is likely more sustainable over time (versus when costly supplements are studyprovided) (30). Further research, however, is needed to examine whether the increase in dietary protein intake behaviors was maintained post-study.

The increase in protein intake among participants was also consistent with the findings of other studies using coaching. These other studies, however, successfully used coaching to help participants improve food choices to reduce risks of conditions such as diabetes, heart disease, and obesity (15-18). In systematic literature reviews, coaching has been shown to significantly impact behavior change including dietary modifications $(15,17)$. Consistent with the Health and Wellness Nurse-coaching Model (28), the weekly coaching sessions used in this study assisted participants in establishing goals related to protein intake at meals, empowering and motivating participants to help them to achieve their goals, and helping participants to identify and arrive at solutions to any obstacles/barriers impeding goal achievement (28, 29).

Small but significant increases in GS and significant reductions in times needed to complete $5 \mathrm{CR}, 3 \mathrm{~mW}$ (gait speed) and TUG were found. These improvements may have resulted from the increased overall protein intake $/ \mathrm{kg}$ body weight, which by week 10 averaged $1.2 \mathrm{~g}$ protein $/ \mathrm{kg}$ body weight, and perhaps from the increased per-meal protein intake, which by week 10 averaged 20 g or more/meal. However, further studies that include a control group and a larger and well-powered sample size are required. The higher protein intakes have been shown to overcome anabolic resistance in muscle protein synthesis that has been observed in older adults (8). Other studies have also shown increases in muscle strength and physical performance (similar to this investigation) as well as increases in muscle mass with higher protein intakes in older adults; however, participants in these other studies were provided directly with supplemental protein sources (amino acids or protein powders) for consumption at selected meals or specific times (10-14, 31).

The findings of this investigation are limited by a number of factors. The sample size was small, included primarily $(75 \%)$ females, and was also not racially or ethnically diverse. The participants also resided in urban areas in South Florida. Diet recalls were not obtained from participants for the 10 weeks prior to the start of the intervention to verify that protein intake was not changed by other factors. Despite these limitations, this unique pilot investigation provides data to inform the development of a well-powered, randomized controlled trial; such a trial may respond to the question of whether the use of nutrition education, diet coaching, and a permeal protein prescription are effective in helping adults improve intake of protein-containing foods and meet recommendations for protein intake and if protein intake improvement translates into clinical benefits (eg, muscle function) for the individuals.

Conflicts of Interest: The authors declare no conflicts of interest.

Funding source: None.

\section{References}

1. Berner LA, Becker G, Wise M, Dot J. Characterization of dietary protein among older adults in the United States: Amount, animal sources, and meal patterns. J Acad Nutr Diet, 2013; 113(6): 809-15.

2. USDA. Agricultural Research Service. Energy intake: percentages of energy from protein, carbohydrate, fat and alcohol by gender and age, what we eat in America, NHANES 2009-2010. 2012. Available from http:/ / www.ars.usda. gov/ba/bhnrc/fsrg

3. Kim B, Schutzler S, Schrader A, Spencer H, Kortebein P, Deutz NEP, Wolfe RR, Ferrando AA. Quantity of dietary protein intake, but not pattern of intake, affects net protein balance primarily through differences in protein synthesis in older adults. Am J Physiol Endocrinol Metab, 2015; 308(1): E21-8.

4. Farsijani S, Morais JA, Payette H, Gaudreau P, Shatenstein B, Gray-Donald $\mathrm{K}$, Chevalier S. Relation between mealtime distribution of protein intake and lean mass loss in free-living older adults of the NuAge study. Am J Clin Nutr, 2016; 104(3): 694-703

5. Farsijani S, Payette H, Morais JA, Shatenstein B, Gaudreau, Chevalier S. Even mealtime distribution of protein intake is associated with greater muscle strength, but not with 3-y physical function decline, in free-living older adults: the Quebec longitudinal study on Nutrition as a Determinant of Successful Aging (NuAge study). Am J Clin Nutr, 2017; 106(1): 113-24.

6. Loenneke JP, Loprinzi PD, Murphy CH, Phillips SM. Per meal dose and frequency of protein consumption is associated with lean mass and muscle performance. Clin Nutr, 2016; 35(6): 1506-11.

7. Cruz-Jentoft AJ, Bahat G, Bauer J, Boirie $Y$, Bruyère $O$, Cederholm T, Cooper C, Landi F, Rolland Y, Sayer AA, Schneider SM, Sieber CC, Topinkova E Vandewoude M, Visser M, Zamboni M; Writing Group for the European Working Group on Sarcopenia in Older People 2 (EWGSOP2), and the Extended Group for EWGSOP2. Sarcopenia: revised European consensus on definition and diagnosis. Age Ageing, 2019; 48(1): 16-31.

8. Wall BT, Gorissen SH, Pennings B, Koopman R, Groen BL, Verdiik LB, van Loon LJC. Aging is accompanied by a blunted muscle protein synthetic response to protein ingestion. PloS One, 2015; 10(11): e014903-e014903.

9. Murphy CH, Oikawa SY, Phillips SM. Dietary protein to maintain muscle mass in aging: a case for per-meal protein recommendations. J Frailty \& Aging, 2016; 5(1): 49-58. 
10. Mamerow MM, Mettler JA, English KL, Casperson SL, Arentson-Lantz E, Sheffield-Moore M, Layman DK, Paddon-Jones D. Dietary protein distribution positively influences $24-\mathrm{h}$ muscle protein synthesis in healthy adults. J Nutr, 2014; 144(6): 876-80.

11. Chanet A, Verlaan S, Salles J, Girauder C, Patrac V, Pidou V, Pouyet C, Hafnaoui N, Blot A, Cano N, Farigon N, Bongers A, Jourdan M, Luiking Y, Walrand S, Boirie Y. Supplementing breakfast with a vitamin D and leucinerich whey protein medical nutrition drink enhances postprandial muscle protein synthesis and muscle mass in healthy older men. J Nutr, 2017; 147(12): 2262-71.

12. Borsheim E, Bui QT, Tissier S, Kobayashi H, Ferrando AA, Wolfe RR. Effect of amino acid supplementation on muscle mass, strength and physical function in elderly. Clin Nutr, 2008; 27(2): 189-195.

13. Dillon EL, Sheffield-Moore M, Paddon-Jones D, Gilkison C, Sanford AP, Casperson SL, Jiang J, Chinkes DL, Urban RT. Amino acid supplementation increases lean body mass, basal muscle protein synthesis, and insulin-like growth factor-1 expression in older women. J Clin Endocrinol Metab, 2009; 94: 1630-1637.

14. Norton C, Toomey C, McCormack WG, Francis P, Saunders J, Kerin E, Jakeman P. Protein supplementation at breakfast and lunch for 24 weeks beyond habitual intakes increases whole-body lean tissue mass in healthy older adults. J Nutr, 2016; 146(1): 65-9.

15. Olsen JM, Nesbitt BJ. Health coaching to improve healthy lifestyle behaviors: an integrative review. Am J Hlth Promotion, 2010; 25(1): e1-e12.

16. Schneider KL, Coons MJ, McFadden HG, Pellegrini CA, DeMott A, Siddique J, Hedeker D, Aylward L, Spring B. Mechanisms of change in diet and activity in the Make Better Choices 1 trial. Health Psychology 2016; Apr 7. doi. org / $10.1037 /$ hea0000333.

17. Hill B, Richardson B, Skouteris H. Do we know how to design effective health coaching interventions: A systematic review of the state of the literature. Am J Hlth Promotion, 2015; 29(5) e1: 58-e168.

18. Vincent AE, Sanchez Birkhead AC. Evaluation of the effectiveness of nurse coaching in improving health outcomes in chronic conditions. Holistic Nursing Practice, 2013; 27(3), 148-161.

19. Borson S, Scanlan J, Brush M, Vitaliano P, Dokmak A. The mini-cog: a cognitive 'vital signs' measure for dementia screening in multi-lingual elderly. Int J Geriatr Psychiatry, 2000; 15: 1021-1027.

20. Kaiser MJ, Bauer JM, Ramsch C, et al. Validation of the Mini Nutritional Assessment Short-Form (MNA®-SF): A practical tool for identification of nutritional status. J Nutr Health Aging, 2009; 13(9): 782-788.

21. Vellas B, Villars H, Abellan G, et al. Overview of the MNA® - Its History and Challenges. J Nutr Health Aging, 2006;10(6):456-465.

22. Stumbo P. Considerations for selecting a dietary assessment system. J Food Compost Anal, 2008; 21(1): S13-S19.

23. ESHA Research. ESHA Food and nutrition databases. Available at: https:/ esha.com/nutrition-database/.

24. Food and Nutrition Board. Dietary Reference Intakes for Energy, Carbohydrate, Fiber, Fat, Protein and Amino Acids. Washington, DC: National Academy Press. 2002.

25. Roberts HC, Denison HJ, Martin HJ, Patel HP, Syddall H, Cooper C Sayer AA. A review of the measurement of grip strength in clinical and epidemiological studies: towards a standardised approach. Age and Ageing, 2011; 40: 423-429.

26. Bohannon RW. Reference values for the Timed Up and Go Test: A descriptive meta-analysis. J Geriatric Physical Therapy, 2006; 29(2): 64.

27. Guralnik JM, Simonsick EM, Ferrucci L, Glynn RJ, Berkman LF, Blazer DG Scherr PA, Wallace RB. A short physical performance battery assessing lower extremity function: association with self-reported disability and prediction of morality and nursing home admission. J Gerontol, 1994; 49:M85-M94.

28. Dossey BM, Schaub BG, Luck S. International Nurse Coach Association (INCA). Nurse coaching: Integrative approaches for health and wellbeing. North Miami, Florida: International Nurse Coach Association, 2015.

29. Hess DR, Dossey BM, Southard ME, Luck S, Schaub BG, Bark, L. The art and science of nurse coaching: The provider's guide to coaching scope and competencies. Silver Spring, MD: American Nurses Association, 2013.

30. Lanza E, Schatzkin A, Daston C, Corle D, Freedman L, Ballard-Barbash $\mathrm{R}$ Caan B, Lance P, Marshall J, Iber F, Shike M, Weissfeld J, Slattery M, Paskett E, Mateski D, Albert P, PPT Study Group. Implementation of a 4-y, high-fiber high-fruit- and-vegetable, low-fat dietary intervention: results of dietary changes in the Polyp Prevention Trial. Am J Clin Nutr, 2001; 74: 387-401.

31. Pennings B, Groen B, de Lange A, Gijsen AP, Zorenc AH, Senden JMG van Loon LJC. Amino acid absorption and subsequent muscle protein accretion following graded intakes of whey protein elderly men. Am J Physiol Endocrinol Metab, 2012; 302: E992-999. 